\title{
High-performance liquid chromatography (HPLC) analysis for flavonoids profiling of Napier grass herbal tea
}

\author{
${ }^{1}$ Ng, K.S., ${ }^{1}$ Mohd Zin, Z., ${ }^{1}$ MohdMaidin, N., ${ }^{2}$ Mamat, H., ${ }^{3}$ Juhari, N.H. and \\ ${ }^{1,}$ Zainol, M.K. \\ ${ }^{1}$ Faculty of Fisheries and Food Science, Universiti Malaysia Terengganu, 21030 Mengabang Telipot, Kuala \\ Nerus, Terengganu \\ ${ }^{2}$ Faculty of Food Science and Nutrition, Universiti Malaysia Sabah, 88400 Kota Kinabalu, Sabah, Malaysia \\ ${ }^{3}$ Faculty of Food Science and Technology, Universiti Putra Malaysia, 43400, UPM Serdang, Selangor, \\ Malaysia
}

\author{
Article history: \\ Received: 29 June 2020 \\ Received in revised form: 8 \\ August 2020 \\ Accepted: 2 September 2020 \\ Available Online: 14 \\ November 2020
}

Keywords:

Napier grass,

HPLC,

Flavonoids,

Herbal tea,

Antioxidant activity

DOI:

https://doi.org/10.26656/fr.2017.5(1).311

\begin{abstract}
Natural plant products are becoming more and more essential in helping to promote safe well-being worldwide. This leads to a substantial rise in the consumption of various herbal teas. The presence of beneficial bioactive ingredients such as flavonoids may be correlated with Napier grass herbal tea having health benefits associated with their intake. Studies have shown that herbal teas have preferentially high antioxidant activity due to the presence of flavonoids in them. The purpose of this study was to identify the Napier grass herbal teas flavonoids prepared under different conditions. Napier grass herbal teas have been formulated using green tea and black tea processes, respectively. The tea samples were extracted in water $\left(95^{\circ} \mathrm{C}, 30 \mathrm{mins}\right)$ and $60 \%(\mathrm{v} / \mathrm{v})$ aqueous methanol (30 mins), respectively. Approximately, $1 \%(\mathrm{v} / \mathrm{v})$ aqueous acetic acid solution (solvent $\mathrm{A})$ and acetonitrile (solvent $\mathrm{B}$ ) were used as the mobile phase. The flow rate was adjusted to 0.7 $\mathrm{mL} / \mathrm{min}$, the column was thermostatically controlled at $28^{\circ} \mathrm{C}$, and the injection column was kept at $20 \mu \mathrm{L}$. HPLC chromatograms were detected using a photodiode array UV detector at $272 \mathrm{~nm}$. Gallic acid, P-coumaric acid, catechin, epigallocatechin gallate, quercetin, rutin, myricetin and kaempferol were found in both Napier grass water and methanolic extracts, respectively. The findings suggested that the HPLC techniques are ideal for the detection and identification of flavonoids in Napier grass teas.
\end{abstract}

\section{Introduction}

Tea is commonly recognized to contain a vast variety of biologically active compounds, such as polyphenols, vitamins, proteins, organic acids, sugars and glycosides, among others (Pan et al., 2003; Kim et al., 2013; Chong et al., 2020). On the other hand, green tea has been recorded for decades, as it contains beneficially active compounds that can combat degenerative diseases (Demeule et al., 2002). Green tea is described as fresh or dried unfermented leaves and is commonly produced with very early shoots, which are almost white in colour and much sought after (Chacko et al., 2010). Napier grass (Pennisetum purpureum), an underutilized plant found in Malaysia which is a large and rapidly growing perennial plant native to Africa and found throughout the world's wet tropics (Reddy, 2017). Several studies have shown that young leaves or tender shoots of Napier grass are potential sources of dietary protein, minerals, vitamins and antioxidants (Akah and Ani, 2014; Akah and Onweluzo, 2014; Ukpabi et al., 2015) that may be ideal for herbal tea. Although it is edible, knowledge on the chemical properties of Napier grass is minimal. Therefore, the research to investigate and classify flavonoids in Napier grass herbal is crucial.

The health benefits ascribed to the consumption of herbal teas may be related to the high content of bioactive ingredients such as flavonoids. Flavonoids are secondary plant metabolites, which can be classified into six subclasses of flavonoids, flavonols, flavanols, isoflavones and anthocyanidins based on their distinction in the heterocyclic C-ring (Hollman, 2004). These compounds have been reported having antioxidant, antiviral and anti-inflammatory activities (Frankel and Finley, 2008). They also showed more potent antioxidative activity than butylated hydroxyanisole (BHA), butylated hydroxytoluene (BHT) and dl- $\alpha-$ 
tocopherol.

HPLC methods became remarkably accepted since HPLC offers the benefits of simultaneous separation and quantification of flavonoid compounds under analysis without the requirement for a preliminary conversion (Kumar, 2017). Qualitative analysis that creates a 'fingerprint' chromatography gathered under ordinary conditions can be valuable for phytochemical quality control. Stefova et al. (2003) mentioned that reversedphase HPLC had been used for plant flavonoids analysis on a variety of occasions, for instance, the content of flavonoids in Napier grass water extract was identified using HPLC by Yu et al. (2007). Likewise, it had been regularly employed in the identification of the phenolic compounds in teas such as green tea (Cheong et al., 2005), oolong tea (Theppakorn et al., 2014) and Mate tea (Bojić et al., 2013). The purpose of this research was, therefore, to identify and quantify some individual flavonoids from Napier grass herbal tea.

\section{Materials and methods}

\subsection{Preparation of Napier grass water extracts}

\subsubsection{Fresh Napier grass sample}

Fresh Napier grass was harvested from Kuala Berang, Terengganu. Only the 4-month-old leaves were collected. The leaves were brushed with tap water and then rubbed away with paper towels to remove water Prior to the analysis, the leaves were permitted to dry at room temperature $\left(25 \pm 1^{\circ} \mathrm{C}\right)$ for 10 mins. The analysis was carried out in triplicate.

Infusion of fresh Napier grass was used as a control in all experiments. Five grams of fresh Napier grass was ground using a waring blender (Waring Commercial, Torrington. CT, USA). Then, it was infused in $200 \mathrm{~mL}$ of distilled water $\left(95^{\circ} \mathrm{C}\right)$ and continuously stirred for 2 mins using a magnetic stirrer $(\mathrm{Ng}$ et al., 2020). The infusion was left to cool for 30 mins of infusion time before filtered through $0.45 \mu \mathrm{m}$ PVDF-syringe filter (Thermo Scientific, Massachusetts, USA).

\subsubsection{Napier grass tea samples}

Control of Napier grass tea was prepared by drying $50 \mathrm{~g}$ of cut Napier grass $(0.5 \mathrm{~cm})$ at $50^{\circ} \mathrm{C}$ for $7 \mathrm{hrs}$. Napier grass green tea was developed by steaming $50 \mathrm{~g}$ of the cut Napier grass $(0.5 \mathrm{~cm})$ for 8 mins. The sample was then placed into a plastic bag and soaked in icy cold water for $30 \mathrm{~s}$ to stop the cooking process. Then, the sample was dried at the determined optimum temperature $\left(50^{\circ} \mathrm{C}\right)$ for $7 \mathrm{hrs}(<6 \%$ moisture content $)$ (Carloni et al., 2013; Lusia Barek et al., 2015 with modifications). For the preparation of Napier grass black tea, cleaned fresh Napier grass was subjected to a withering process at $30^{\circ} \mathrm{C}$ for 30 mins until $70 \%$ moisture content was obtained. A total of $50 \mathrm{~g}$ cut Napier grass $(0.5 \mathrm{~cm})$ was sprinkled with distilled water in $1: 1$ $(\mathrm{w} / \mathrm{v})$ ratio before undergoing the oxidation-fermentation process for $9 \mathrm{hrs}$ at $25^{\circ} \mathrm{C}$. Then, the sample was dried at the determined optimum temperature $\left(50^{\circ} \mathrm{C}\right)$ for $7 \mathrm{hrs}(<$ 6\% moisture content) (Ma et al., 2014; Lusia Barek et al., 2015 with modifications). Then, all the dried Napier grass samples were ground and sieved through a $1 \mathrm{~mm}$ metal sieve. Powdered Napier grass tea $(0.1 \mathrm{~g})$ was infused in $10 \mathrm{~mL}$ distilled water $\left(95^{\circ} \mathrm{C}\right)$ and continuously stirred for 2 mins using a magnetic stirrer. The infusion was left to cool for 30 mins of infusion time before filtered through $0.45 \mu \mathrm{m}$ PVDF-syringe filter (Thermo Scientific, Massachusetts, USA).

\subsection{Preparation of Napier grass methanolic extracts}

\subsubsection{Fresh Napier grass sample}

Fresh Napier grass of $5 \mathrm{~g}$ was ground using a waring blender (Waring Commercial, Torrington. CT, USA). Then it was infused in $200 \mathrm{~mL} 60 \%$ (v/v) aqueous methanol and continuously stirred for 2 mins using a magnetic stirrer. The infusion was left for 30 mins of infusion time before filtered through $0.45 \mu \mathrm{m}$ PVDFsyringe filter (Thermo Scientific, Massachusetts, USA).

\subsubsection{Napier grass tea samples}

The Napier grass tea control was prepared by drying $50 \mathrm{~g}$ of cut Napier grass $(0.5 \mathrm{~cm})$ at $50^{\circ} \mathrm{C}$ for $7 \mathrm{hrs}$. Napier grass green tea was prepared by steaming $50 \mathrm{~g}$ of the cut Napier grass $(0.5 \mathrm{~cm})$ for 8 mins. The sample was then placed into a plastic bag and soaked in icy cold water for $30 \mathrm{~s}$ to stop the cooking process. Then, the sample was dried at the determined optimum temperature $\left(50^{\circ} \mathrm{C}\right)$ for $7 \mathrm{hrs}(<6 \%$ moisture content $)$ (Carloni et al., 2013 with modifications).

Cleaned fresh Napier grass for Napier grass black tea was subjected to a $30^{\circ} \mathrm{C}$ withering process for $30 \mathrm{mins}$ until a $70 \%$ moisture content was obtained. Approximately, $50 \mathrm{~g}$ of cut Napier grass $(0.5 \mathrm{~cm})$ was sprinkled with distilled water in a ratio of $1: 1(\mathrm{w} / \mathrm{v})$ before undergoing room temperature oxidationfermentation for $9 \mathrm{hrs}$. The sample was then dried at the specified optimum temperature $\left(50^{\circ} \mathrm{C}\right)$ for $7 \mathrm{hrs}(<6 \%$ humidity) (Hafezi et al., 2006). All the dried samples of Napier grass were then ground and sewn through a $1 \mathrm{~mm}$ metal sieve. Powdered Napier grass tea $(0.1 \mathrm{~g})$ was infused with aqueous methanol in $10 \mathrm{~mL} 60 \%(\mathrm{v} / \mathrm{v})$ and continuously stirred for 2 mins with a magnetic stirrer. The infusion was left for 30 mins of infusion before filtering through a PVDF filter of $0.45 \mu \mathrm{m}$ (Thermo Scientific, Massachusetts, USA). 


\subsection{Preparation of standard solutions}

The phenolic acids (gallic acid, caffeic acid, catechin and P-coumaric acid), flavonoids (epigallocatechin gallate, rutin, myricetin, quercetin, kaempferol and naringenin) were purchased from ChemFaces. The solvents such as glacial acetic acid, HPLC grade acetonitrile and HPLC grade methanol were purchased from R\&M Chemicals, HmbG Chemicals and Fisher Chemicals, respectively. The stock solution of concentration $1 \mathrm{mg} / \mathrm{mL}(\mathrm{w} / \mathrm{v}, 1000 \mathrm{ppm})$ was prepared by dissolving $1 \mathrm{mg}$ of standard in $60 \%(\mathrm{v} / \mathrm{v})$ methanol. The standard working solution $(\mathrm{v} / \mathrm{v}, 20 \mathrm{ppm})$ was then prepared by further dilution of the stock solution with $60 \%(\mathrm{v} / \mathrm{v})$ methanol. The standards were then filtered through a $0.45 \mu \mathrm{m}$ PVDF-syringe filter (Thermo Scientific, Massachusetts, USA).

\subsection{Chromatographic analysis of phenolic acids and} flavonoids of Napier grass extracts

Chromatographic analysis of phenolic acids and flavonoids were carried out using a modified method of Mohd Zainol et al. (2009) and Seal (2016). Approximately, $1 \%(\mathrm{v} / \mathrm{v})$ aqueous acetic acid solution (solvent A) and acetonitrile (solvent B) were used as the mobile phase. The flow rate was adjusted to $0.7 \mathrm{~mL} / \mathrm{min}$, the column was thermostatically controlled at $28^{\circ} \mathrm{C}$, and the injection column was kept at $20 \mu \mathrm{L}$. Gradient elution was performed by varying the proportion of solvent $\mathrm{B}$ to solvent $\mathrm{A}$. The gradient elution was then changed from $10 \%$ to $63 \% \mathrm{~B}$ in a linear fashion for $11 \mathrm{mins}, 63 \%$ was maintained for 10 mins. The elution was increased to $90 \%$ in 26 mins. The composition back to the initial condition (solvent B: solvent A: 10: 90) was achieved in $31 \mathrm{~min}$ and allowed to run for another 5 mins before the injection of the next sample. Total analysis time per sample was 36 mins. HPLC chromatograms were detected using a photodiode array UV detector at 272 $\mathrm{nm}$.

HPLC analyses were performed with Shimadzu Prominence (Kyoto, Japan) high-performance liquid chromatography (HPLC) comprising a degassing unit (DGU-20A5R), LC-20AT pumps, SIL-20AHT autosamplers, CBM-20A controller, SPD-20A UV-Vis detectors, RF-20A fluorescence detectors and CTO10AS VP column oven. Reverse-phase separations were carried out using a Hypersil Gold $\mathrm{C}_{18}$ column $(250$ x 4.6 $\mathrm{mm}$ I.D, $5 \mu \mathrm{m}$ ) (Thermo Scientific, Massachusetts, USA).

\subsection{Statistical analysis}

Data were expressed as means \pm standard deviation (SD) of triplicates analysis. All data were submitted to one-way analysis of variance (ANOVA) using SPSS (version 20) software. The values were considered to be significantly different when $\mathrm{P}<0.05$. Comparisons of means were carried out using Fisher LSD, and the data were presented in the form of mean \pm standard deviation (Mamat et al., 2018).

\section{Results and discussion}

\subsection{High-performance liquid chromatography (HPLC) condition}

Figure 1 shows the chromatogram of the phenolic acid and flavonoid standard mixture recorded at $272 \mathrm{~nm}$. In order to efficiently separate the compounds within a shorter analysis time, compositions of mobile phase A ( $1 \%$ acetic acid) and $\mathrm{B}(100 \%$ acetonitrile), flow rate and $\mathrm{pH}$ of acidified deionized water were utilized. The resolution and analysis time were improved by adjusting the elution program until a satisfactory result was achieved. The study also found that the combination of gradient and isocratic elution gave a better result. Most of the flavonoids were eluted out within 11 to $21 \mathrm{mins}$ with $63 \%$ acetonitrile. The total analysis time for each sample was 36 mins. Chromatograms of 8 standards of phenolic compounds, namely gallic acid (4.78 mins), catechin (10.09 mins), epigallocatechin gallate (11.32 mins), rutin (12.07 mins), P-coumaric acid (12.86 mins), myricetin (14.16 mins), quercetin (15.58 mins) and kaempferol (16.88 mins) were detected. They were successfully eluted at different retention times by the combination of gradient and isocratic elution using 1\% ( $\mathrm{v} / \mathrm{v})$ acetic acid and acetonitrile as mobile phase. The targeted phenolic compounds in this study can be classified into phenolic acids (gallic acid and P-coumaric acid), flavan-3-ols (catechin and epigallocatechin gallate), flavonols (rutin, myricetin, quercetin and kaempferol).

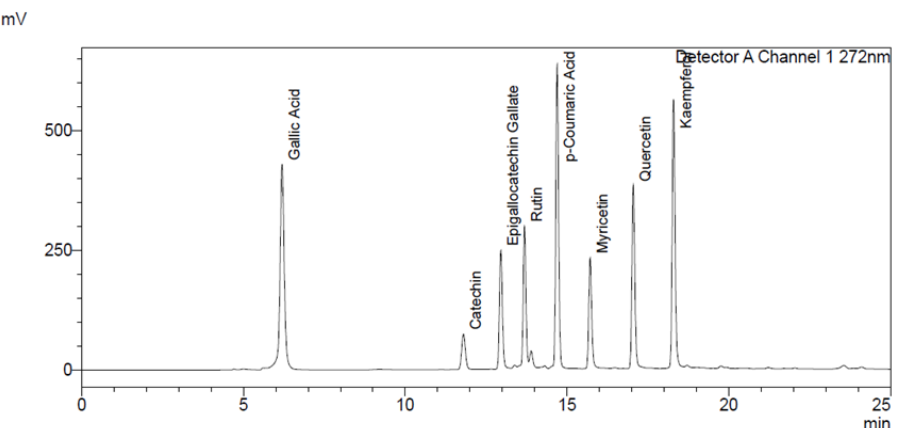

Figure 1. Chromatogram of phenolic acid and flavonoid standard mixture

Several dilutions of catechins $(40,60,80,100$ and $200 \mathrm{ppm})$ were used as external criteria for the determination of linearity and accuracy of the HPLC method (Figure 2). The calibration curve was built by plotting peak area against standard concentration. The 
Table 1. Concentration (ppm) of phenolics and flavonoids in Napier grass samples

\begin{tabular}{|c|c|c|c|c|c|c|c|c|}
\hline Samples & Gallic acid & Catechin & EGCG & Rutin & $\begin{array}{l}\text { P-Coumaric } \\
\text { acid }\end{array}$ & Myricetin & Quercetin & Kaempferol \\
\hline A & $0.46 \pm 0.02^{b}$ & $47.42 \pm 8.78^{a}$ & $21.22 \pm 0.47^{\mathrm{a}}$ & $28.42 \pm 0.66^{a}$ & $4.71 \pm 0.01^{b}$ & $1.71 \pm 0.17^{b}$ & $0.39 \pm 0.02^{b}$ & $0.31 \pm 0.02^{\mathrm{b}}$ \\
\hline B & $0.63 \pm 0.07^{\mathrm{b}}$ & $2.06 \pm 0.12^{\mathrm{b}}$ & $12.60 \pm 0.21^{\mathrm{bc}}$ & $3.00 \pm 0.86^{\mathrm{e}}$ & $1.13 \pm 0.23^{\mathrm{d}}$ & $0.73 \pm 0.03^{c}$ & $0.58 \pm 0.01^{\mathrm{a}}$ & $0.06 \pm 0.02^{\mathrm{ef}}$ \\
\hline $\mathrm{C}$ & $0.17 \pm 0.02^{\text {cde }}$ & $1.71 \pm 0.20^{\mathrm{b}}$ & $7.94 \pm 0.25^{\mathrm{de}}$ & $4.21 \pm 0.25^{\mathrm{cd}}$ & $1.20 \pm 0.06^{\mathrm{d}}$ & $0.33 \pm 0.04^{\mathrm{d}}$ & $0.23 \pm 0.00^{\mathrm{cd}}$ & $0.04 \pm 0.01^{\mathrm{f}}$ \\
\hline $\mathrm{D}$ & $0.01 \pm 0.00^{\mathrm{e}}$ & $3.56 \pm 0.08^{b}$ & $7.34 \pm 0.11^{\mathrm{e}}$ & $4.83 \pm 0.12^{\mathrm{c}}$ & $1.56 \pm 0.58^{\mathrm{d}}$ & $0.60 \pm 0.01^{\mathrm{cd}}$ & $0.10 \pm 0.00^{\mathrm{d}}$ & $0.07 \pm 0.02^{\mathrm{ef}}$ \\
\hline E & $0.02 \pm 0.01^{\mathrm{de}}$ & $5.94 \pm 0.93^{\mathrm{b}}$ & $21.09 \pm 0.07^{\mathrm{a}}$ & $9.21 \pm 0.08^{\mathrm{b}}$ & $8.09 \pm 1.74^{\mathrm{a}}$ & $1.84 \pm 0.01^{\mathrm{b}}$ & $0.38 \pm 0.03^{b}$ & $0.23 \pm 0.02^{\mathrm{c}}$ \\
\hline $\mathrm{F}$ & $0.19 \pm 0.15^{\mathrm{c}}$ & $5.22 \pm 0.79^{b}$ & $10.13 \pm 0.11^{\mathrm{cd}}$ & $4.80 \pm 0.25^{\mathrm{c}}$ & $1.63 \pm 0.62^{\mathrm{d}}$ & $0.79 \pm 0.18^{\mathrm{c}}$ & $0.37 \pm 0.03^{b c}$ & $0.12 \pm 0.01^{\mathrm{de}}$ \\
\hline G & $0.18 \pm 0.01^{\mathrm{cd}}$ & $2.76 \pm 0.37^{b}$ & $13.17 \pm 1.96^{\mathrm{b}}$ & $2.94 \pm 0.12^{\mathrm{e}}$ & $4.01 \pm 0.09^{\mathrm{bc}}$ & $5.68 \pm 0.02^{\mathrm{a}}$ & $0.45 \pm 0.10^{\mathrm{ab}}$ & $0.14 \pm 0.01^{\mathrm{d}}$ \\
\hline $\mathrm{H}$ & $1.58 \pm 0.03^{\mathrm{a}}$ & $2.20 \pm 0.26^{\mathrm{b}}$ & $10.30 \pm 1.71^{\mathrm{cd}}$ & $3.08 \pm 0.30^{\mathrm{de}}$ & $2.01 \pm 2.68^{\mathrm{cd}}$ & $5.94 \pm 0.19^{\mathrm{a}}$ & $0.59 \pm 0.09^{\mathrm{a}}$ & $0.46 \pm 0.05^{\mathrm{a}}$ \\
\hline
\end{tabular}

Values are expressed as means \pm standard deviation. Values with different superscript letters in columns are statistically significant from each other at $\mathrm{P}<0.05$.

Water extracts (A-D): $\mathrm{A}=$ Fresh Napier grass water extract, $\mathrm{B}=$ Water extract of Napier grass dried at $50^{\circ} \mathrm{C}, \mathrm{C}=\mathrm{Water}$ extract of Napier grass green tea ( 6 mins steaming time), $\mathrm{D}=$ Water extract of Napier grass black tea ( $9 \mathrm{~h}$ fermentation time).

Methanolic extracts $(\mathrm{E}-\mathrm{H}): \mathrm{E}=$ Fresh Napier grass methanolic extract, $\mathrm{F}=$ Methanolic extract of Napier grass dried at $50^{\circ} \mathrm{C}, \mathrm{G}=$ Methanolic extract of Napier grass green tea (6 mins steaming time), $\mathrm{H}=$ Methanolic extract of Napier grass black tea (9 hrs fermentation time).

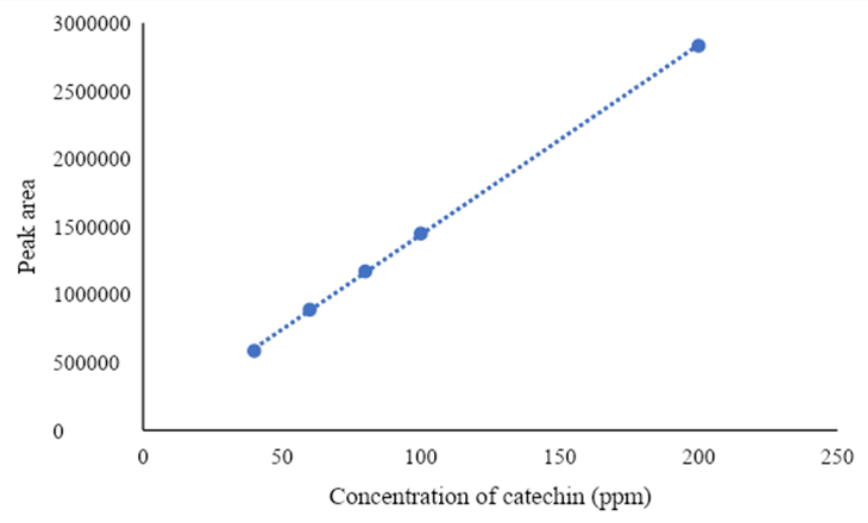

Figure 2. Calibration curve of external standard (catechin)

correlation coefficient square showed that $\mathrm{R}>0.9998$ indicates the system's high linearity and precision.

\subsection{Determination of individual flavonoids}

Table 1 shows the concentration of phenolics and flavonoids in Napier grass samples. The amount of gallic acid and quercetin showed no significant difference among the samples, respectively indicating tea processing methods did not affect the amount of gallic acid and quercetin. The highest amount of flavonoids detected was catechin $(42.42 \pm 8.78 \mathrm{ppm})$, accompanied by routine $(28.42 \pm 0.66 \mathrm{ppm})$ and epigallocatechin gallate $(21.22 \pm 0.47 \mathrm{ppm})$ contained in sample A water extract (fresh Napier grass) compared to other water and methanol extracts. The highest amount of rutin $(21.00 \pm 0.66 \mathrm{ppm})$, epigallocatechin gallate $(17.736 \pm 6.28$ ppm), P-coumaric acid (6.09 $\pm 3.02 \mathrm{ppm})$, myricetin $(1.71 \pm 4.81 \mathrm{ppm})$, gallic acid $(0.74 \pm 0.48)$, quercetin $(0.39 \pm 0.02 \mathrm{ppm})$ and kaempferol $(0.31 \pm 0.02 \mathrm{ppm})$ were also found in fresh Napier grass among water extracts. Methanolic extract of fresh Napier grass showed the highest amount of epigallocatechin gallate $(21.09 \pm 0.07$ $\mathrm{ppm})$, rutin $(32.33 \pm 0.08 \mathrm{ppm})$ and P-coumaric acid
$(8.09 \pm 4.40 \mathrm{ppm})$. In contrast, methanolic extract of $\mathrm{E}$ (fresh Napier grass) showed the highest amount of Pcoumaric acid $(8.09 \pm 1.74 \mathrm{ppm})$ among the water and methanolic extracts $(\mathrm{A}-\mathrm{H})$. Whereas, the highest amount of gallic acid $(1.58 \pm 0.03 \mathrm{ppm})$, myricetin $(5.94 \pm 0.19$ ppm), quercetin $(0.59 \pm 0.09 \mathrm{ppm})$ and kaempferol $(0.46 \pm 0.05 \mathrm{ppm})$ were observed in $\mathrm{H}$ (methanolic extract of Napier grass black tea). High amounts of certain flavonoids in methanolic extracts showed the effectiveness of the extraction with $60 \%$ methanol. Approximately $60 \%$ methanol was used as an extraction solvent for plant phenolic compounds in previous studies as it was found to extract the phenolic compounds efficiently (Mohd Zainol et al., 2009; Pyrzynska and Sentkowska, 2015) and was also reported as a suitable solvent for phytochemical extraction (Chigayo et al., 2016).

This study also utilized the water and aqueous mixture of $60 \%$ methanol, which were used as extraction solvents. The combination of water and alcohol have been reported to be efficient in the extraction of phenolic compounds (Grujic et al., 2012; Toudert et al., 2017). This is because some flavonoids are water-soluble, and others are not. The water solubility of certain flavonoids such as myricetin, kaempferol and luteolin are poor (Kwon et al., 2010). Although glycosides of flavonoids have increased their water solubility, their water solubility is limited (Bilia et al., 2014). In contrast, flavan-3-ols such as catechin can directly be extracted with water (Andersen and Markham, 2006). Thus, there might be some limitations by using mono-component solvent as the polarity of phenolic compounds are different. In this case, mixed organic solvent-water mixtures could be a good alternative for the extraction of flavonoids (Jabbari and Gharib, 2011). Besides, acids were not used in flavonoids extraction because flavan-3- 
ols and flavanones are sensitive to acids (Yang et al., 2008).

In this study, the Napier grass samples were found in lower concentrations of kaempferol and quercetin compared with the Napier teas. This can be explained by the flavonoid's stability, which was significantly impacted by the thermal extraction process. Besides, rutin showed greater stability than that of its quercetinlike aglycon form (Biesaga and Pyrzynska, 2013). The chemical structure of the flavonoids also had a significant impact on its stability. Higher number of hydroxyl groups in flavonoid compounds resulted in a reduction in the stability of the compound. In contrast, a sugar moiety and methoxyl groups added stability to the flavonoids. Biesaga (2011) also stated that the hydroxyl group location also affected the stability of the compound. For example, flavonoids with the same number of hydroxyl groups, such as kaempferol (flavonol) with a hydroxyl group in $\mathrm{A}, \mathrm{B}$, and $\mathrm{C}$ rings showed more prone to degradation than luteolin (flavonone) with hydroxyl groups in A and $\mathrm{C}$ rings only.

\section{Conclusion}

The HPLC study confirmed the presence of flavonoids and phenolic compounds in selected Napier grass samples. Gallic acid, P-coumaric acid, catechin, epigallocatechin gallate, quercetin, rutin, myricetin and kaempferol were found in both Napier grass water and methanolic extracts, respectively. The amount of gallic acid and quercetin showed no significant difference among the samples, respectively indicating tea processing methods were not affected by the amount of gallic acid and quercetin. The highest amount of catechin was found in the water extract of fresh Napier grass. The highest amount of rutin, epigallocatechin gallate, Pcoumaric acid, myricetin, gallic acid, quercetin and kaempferol were also found in fresh Napier grass among water extracts. Methanolic extract of fresh Napier grass showed the highest amount of epigallocatechin gallate, rutin and $\mathrm{P}$-coumaric acid.

\section{Conflict of interest}

The authors declare no conflict of interest in conducting this study.

\section{Acknowledgements}

The research was supported by a grant (NRGS/53131) from the Research Council of Universiti Malaysia Terengganu. We are grateful to the Faculty of Fisheries and Food Sciences and the Centre of Research and Field Service for providing basic facilities and resources for this work as well as CW Agro Sdn. Bhd. for providing the Napier grass.

\section{References}

Akah, N.P. and Ani, J.C. (2014). The role of elephant grass (Pennisetum purpureum L. Schumach) "achara" in global food security. International Conference on Biodiversity and the UN Millennium Development Goals: Biodiversity and Food Security. Aix-en-Provence, France.

Akah, N.P. and Onweluza, J.C. (2014). Evaluation of water-soluble vitamins and optimum cooking time of fresh portions of elephant grass (Pennisetum purpureum L. Schumach) shoot. Nigerian Food Journal, 32(2), 120-127. https://doi.org/10.1016/ S0189-7241(15)30127-2

Andersen, Ø. and Markham, K.R. (Eds.). (2006). Flavonoids: Chemistry, biochemistry and applications. Boca Raton: CRC Press.

Biesaga, M. (2011). Influence of extraction methods on stability of flavonoids. Journal of Chromatography A, 1218(18), 2505-2512. https://doi.org/10.1016/ j.chroma.2011.02.059

Biesaga, M. and Pyrzynska, K. (2013). Stability of bioactive polyphenols from honey during different extraction methods. Food Chemistry, 136(1), 46-54. https://doi.org/10.1016/j.foodchem.2012.07.095.

Bilia, A.R., Isacchi, B., Righeschi, C., Guccione, C. and Bergonzi, M.C. (2014). Flavonoids loaded in nanocarriers: An opportunity to increase oral bioavailability and bioefficacy. Food and Nutrition Sciences, 5, 1212-1227. https://doi.org/10.4236/ fns.2014.513132.

Bojić, M., Haas, V.S., Šarić, D. and Maleš, Ž. (2013). Determination of flavonoids, phenolic acids, and xanthines in Mate tea (Ilex paraguariensis St.-Hil.). Journal of Analytical Methods in Chemistry, 2013, 658596. https://doi.org/10.1155/2013/658596

Carloni, P., Tiano, L. Padella, L., Bacchetti, T., Customu, C., Kay, A. and Damiani, E. (2013). Antioxidant activity of white, green and black tea obtained from the same tea cultivar. Food Research International, 53(2), 900-908. https:// doi.org/10.1016/j.foodres.2012.07.057

Cheong, W.J., Park, M.H., Kang, G.W., Ko, J.H. and Seo, Y.J. (2005). Determination of catechin compounds in Korean green tea infusions under various extraction conditions by high performance liquid chromatography. Bulletin of the Korean Chemical Society, 26(5), 747-754. https:// doi.org/10.5012/bkcs.2005.26.5.747.

Chigayo, K., Mojapelo, P.E.L., Mnyakeni-Moleele, S. 
and Misihairabgwi, J.M. (2016). Phytochemical and antioxidant properties of different solvent extracts of Kirkia wilmsii tubers. Asian Pacific Journal of Tropical Biomedicine, 6(12), 1037-1043. https:// doi.org/10.1016/j.apjtb.2016.10.004

Chacko, S.M., Thambi, P.T., Kuttan, R. and Nishigaki, I. (2010). Beneficial effects of green tea: A literature review. Chinese Medicine, 5(1), 13. https:// doi.org/10.1186/1749-8546-5-13

Chong, K.H, Majid, N.I., Mohd Yusof, H., Zainol, M.K., Mohamad, H. and Mohd Zin, Z. (2020). Catechin profile and hypolipidemic activity of Morinda citrifolia leaf water extract. Heliyon, 6(6), e04337. https://doi.org/10.1016/j.heliyon.2020.e04337

Demeule, M., Michaud-Levesque, J., Annabi, B., Gingras, D., Boivin, D., Jodoin, J., Lamy, S., Bertrand, Y. and Beliveau, R. (2002). Green Tea Catechins as Novel Antitumor and Antiangiogenic Compounds. Current Medicinal Chemistry-AntiCancer Agents, 2(4), 441-463. https:// doi.org/10.2174/1568011023353930

Frankel, E.N. and Finley, J.W. (2008). How to standardize the multiplicity of methods to evaluate natural antioxidants. Journal of Agricultural and Food Chemistry, 56(13), 4901-4908. https:// doi.org/10.1021/jf800336p

Grujic, N., Lepojevie, Z., Srdjenovic, B., Vladic, J. and Sudji, J. (2012). Effects of different extraction methods and conditions on the phenolic composition of mate tea extracts. Molecules, 17, 2518-2528. https://doi.org/10.3390/molecules 17032518

Hafezi, M., Nasernejad, B. and Vahabzadeh, F. (2006). Optimization of fermentation time for Iranian black tea production. Iranian Journal of Chemistry and Chemical Engineering, 25(1), 39-44.

Hollman, P.C.H. (2004). Absorption, bioavailability, and metabolism of flavonoids. In Pharmaceutical Biology, 42(Sup. 1), 74-83. https:// doi.org/10.3109/13880200490893492

Jabbari, M. and Gharib, F. (2011). Solute-solvent interaction effects on protonation equilibrium of some water-insoluble flavonoids. Journal of Solution Chemistry, 40(4), 561-574. https://doi.org/10.1007/ s10953-011-9667-5

Kim, M.J., John, K.M., Choi, J.N., Lee, S., Kim, A.J., Kim, Y.M and Lee, C.H. (2013). Changes in secondary metabolites of green tea during fermentation by Aspergillus oryzae and its effect on antioxidant potential. Food Research International, 53(2), 670-677. https://doi.org/10.1016/ j.foodres.2012.12.053

Kumar, B.R. (2017). Application of HPLC and ESI-MS techniques in the analysis of phenolic acids and flavonoids from green leafy vegetables (GLVs). Journal of Pharmaceutical Analysis, 7(6), 349364. https://doi.org/10.1016/j.jpha.2017.06.005

Kwon, Y., Kim, H., Park, S. and Jung, S. (2010). Enhancement of solubility and antioxidant activity of some flavonoids based on the inclusion complexation with sulfobutylether $\beta$-cyclodextrin. Bulletin of the Korean Chemical Society, 31(10), 3035-3037. https://doi.org/10.5012/ bkcs.2010.31.10.3035

Lusia Barek, M., Hasmadi, M., Zaleha, A.Z. and Mohd Fadzelly, A.B. (2015). Effect of different drying methods on phytochemicals and antioxidant properties of unfermented and fermented teas from Sabah Snake Grass (Clinacanthus nutans Lind.) leaves. International Food Research Journal, 22(2), 661-670.

Ma, L.M., Dobhal, S. and Timmons, C. (2014). Dried teas and herbs. In Gurtler, J., Doyle, M., Kornacki, J. (Eds.). The Microbiological Safety of Low Water Activity Foods and Spices, p. 329-344. New York, USA: Springer. https://doi.org/10.1007/978-1-49392062-4_17

Mamat, H., Akanda, J.M.H., Zainol, M.K. and Yu, A.I. (2018). The influence of seaweed composite flour on the physicochemical properties of muffin. Journal of Aquatic Food Product Technology, 27(5), 635-642. https:// doi.org/10.1080/10498850.2018.1468841.

Mohd Zainol, M.K., Abdul-Hamid, A., Abu Bakar, F. and Pak Dek, S. (2009). Effect of different drying methods on the degradation of selected flavonoids in Centella asiatica. International Food Research Journal, 16, 531-537.

Pan, X., Niu, G. and Liu, H. (2003). Microwave-assisted extraction of tea polyphenols and tea caffeine from green tea leaves. Chemical Engineering and Processing: Process Intensification, 42(2), 129133. https:// doi.org/10.1016/s0255-2701(02)000375

Pyrzynska, K. and Sentkowska, A. (2015). Recent developments in the HPLC separation of phenolic food compounds. Critical Reviews in Analytical Chemistry, 45, 41-51. https:// doi.org/10.1080/10408347.2013.870027

Reddy, P.S. (2017). Pearl millet, Pennisetum glaucum (L.). In Patil, J.V. (Ed.), Millets and sorghum: Biology and Genetic Improvement, p. 51. United Kingdom: John Wiley and Sons.

Seal, T. (2016). Quantitative HPLC analysis of phenolic acids, flavonoids and ascorbic acid in four different solvent extracts of two wild edible leaves, Sonchus 
arvensis and Oenanthe linearis of North-Eastern region in India. Journal of Applied Pharmaceutical Science, 6(2), 157-166. https://doi.org/10.7324/ JAPS.2016.60225

Stefova, M., Stafilov, T. and Kulevanova, S. (2003). HPLC analysis of flavonoids. In Cazes, J. (Ed.). Encyclopedia of Chromatography, p. 113 - 119. New York: Marcel Dekker, Inc.

Theppakorn, T., Luthfivyyah, A. and Ploysri, K. (2014). Simultaneous determination of caffeine and 8 catechins in oolong teas produced in Thailand. International Food Research Journal, 21(5), 2055 2061.

Toudert, N., Zaiter, A., Djilani, E.D., Dada, N., Djilano, A. and Dicko, A. (2017). Impact of methanol-water ratio of leaf and root extracts of Ampelodesmos mauritanica on the antioxidant activity, and effect of different solvent extraction on phenolic compounds quantification. Acta Scientific Nutritional Health, 1 (5), 3-7. https://doi.org/10.3390/antiox8120597

Ukpabi, U.J., Ofoeze, M.A., Uchechukwu, N., Ezeama, C.F., Edoga, H. and Nwosu, K.I. (2015). Potentials of naturally sheathed young leaves of Napier grass (Pennisetum purpureum) varieties as feeding materials in Nigeria. American Journal of Agricultural Science, 2(3), 97-102.

Yang, R.Y., Lin, S. and Kuo, G. (2008). Content and distribution of flavonoids among 91 edible plant species. Asia Pacific Journal of Clinical Nutrition, 17(S1), 275-279.

Yu, H.M., Wang, B.S., Chu, H.L., Chang, L.W., Yen, W.J., Lin, C.J. and Duh, P.D. (2007). Napier grass (Pennisetum purpureum S.) protects oxidative damage of biomolecules and modulated antioxidant enzyme activity. Food Chemistry, 105(4), 1364 1374. https://doi.org/10.1016/ j.foodchem.2007.05.003 